\title{
De Vlaamse klok uit Pencran (1365)
}

Joseph Strubbe ( ${ }^{\circ}$ Brugge, 14 december 1885), de oudste broer van wijlen prof. dr. Egied Strubbe, is tijdens de eerste wereldoorlog onderpastoor geweest op het Bretoense eiland Ouessant, in vervanging van de twee gemobiliseerde onderpastoors. In de parochieregisters komt zijn handtekening de eerste maal voor op 6 mei 1916, de laatste maal op 28 oktober 1918. Onderpastoor Jozef Strubbe stierf op 14 december 1918 te Brest als slachtoffer van de Spaanse griep; hij was juist 33 jaar oud. Daar hij gevraagd had begraven te worden op zijn duurbaar eiland - hij had Bretoens geleerd om dichter bij de bevolking te staan werd zijn stoffelijk overschot op 29 april 1919 naar Ouessant overgebracht. Op zijn graf hebben de dankbare inwoners een marmeren gedenkplaat onthuld, voorzien van een opschrift in het Bretoens ${ }^{1}$. „On garde de lui le meilleur

1. Joseph STRUBBE

Ganet e BRUGES (Belgique) d'ar 14 a viz

Kerzu 1885, maro e presbital Sant-Martin, BREST, d'ar 14 a viz Kerzu 1918.

Beleg eus bro Belgique, deuet e Frans gant e genvroidi epad ar brezel :

1914 - 1918

bet Kure e parrez EUSSA : 1916-1918, e leac'h men deuz dispignet e nerz hag e iec'hed.

Falvezet eo bet gantan e chomfe e gorf

e douar EUSSA etouez e vignouned da c'hortoz ar varn diveza.

« Evangelizare pauperibus, misit me sanare contritos corde » (St-Matt.)

PEDIT DOUE EVITAN.

Volgens de door pastoor-deken F. Roué medegedeelde Franse vertaling, luidt de tekst in het Nederlands aldus : "Joseph Strubbe, geboren te Brugge (België) op 14 december 1885, overleden in de pastorij van Saint-Martin, Brest, op 14 december 1918. Priester uit 
souvenir" schreef pastoor-deken F. Roué ons op 20 augustus 1971 , „et sa tombe est toujours fleurie par des familles auxquelles il a fait le plus grand bien."

Deze gebeurtenissen kunnen wel mede de bijzondere belangstelling verklaren die prof. Strubbe had voor Bretagne, een volkskundig-rijke streek die de ,hoofdman van de Westvlaamse folkloristen" op vele wijzen aansprak, getuige ook zijn rijke verzameling postkaarten over Bretagne die geheel of gedeeltelijk van zijn broer Jozef afkomstig kan zijn.

Toen we hem in augustus 1970 , enkele maanden vóór zijn overlijden, vertelden dat we op 23 juli in de kerk van Pencran geweest waren om een afwrijfsel te maken van het opschrift van de uit 1365 daterende Vlaamse klok, was het dan ook niet enkel uit belangstelling voor palaeografie en epigrafie dat hij voorstelde om een kopie van het opschrift in ons tijdschrift op te nemen. Dat het in deze aflevering zou gebeuren, heeft geen van ons beiden toen vermoed.

De klok hangt in de toren van de kerk van Notre-Dame te Pencran, een op een heuvel gelegen dorpje op een tiental $\mathrm{km}$. van de zee, in de meest Bretoense streek van Bretagne, de Finistère. Naar de kerk uit 1553, bevinden zich binnen het beluik van het kerkhof nog het knekelhuis uit 1594 en twee kalvaries - waarvan één uit 1521 - , typische Bretoense monumenten waaraan het gebied nog bijzonder rijk is.

De klok is, zonder kroon, ca. $88 \mathrm{~cm}$. hoog en heeft een diameter van $105 \mathrm{~cm}$. Op de bovenflank staat een één-regelige schriftband, aan de boven- en onderzijde begrensd door twee sierringen; verder zijn er nog een faussure-band en twee sierringen aan de onderkant van de slagring. Het opschrift is gesteld in gotische majuskels; aan het begin staat

België, in Frankrijk gekomen met zijn landgenoten tijdens de oorlog 1914-1918, onderpastoor van de parochie Ouessant : 1916-1918, waar hij zijn kracht en gezondheid heeft opgeofferd. Hij heeft verlangd dat zijn lichaam zou rusten in de grond van Ouessant bij zijn vrienden, in afwachting van het algemeen oordeel. Evangelizare... Bidt God voor hem. » 
een kruis en tussen elk woord als scheidingsteken drie onder elkaar geplaatste ruitjes. De streepjes voor de afkortings-n en de ablatief-o in het jaartal staan tussen de twee bovenste sierringen. Aangezien de letters van het opschrift duidelijke verschillen vertonen, mogen we aannemen dat de wassen letters die op de valse klok geplaatst werden, niet in matrijzen gegoten maar met de hand vervaardigd waren. Het opschrift van deze in 1365 door de gebroeders Daniel en Rogerus uit Kortrijk gegoten Mariaklok is niet ongepubliceerd, maar de tekst is nooit helemaal nauwkeurig weergegeven. Het opschrift luidt als volgt :

„† MARIA : DANIEL : ET : ROGERVS : FRATER : EIVS : DE : CVRTRACO : FECERV̄T : NOS : ANNO : $\mathrm{DN} I$ : $\mathrm{M}^{\circ}: \mathrm{CCC}^{\circ} \mathrm{LXV}^{\circ}$ ".

In 1913 werd de klok door een Fransman, de h. L. Lecureux, gesignaleerd aan de Geschied- en Oudheidkundige Kring van Kortrijk, met de vraag of men iets wist over de klokkengieters Maria Damel en haar broeder Roger. Op een vergadering van de kring op 27 november 1913, werd over de lezing van dit klokkenopschrift van gedachten gewisseld; men kwam tot het besluit dat Maria de naam van de klok was en dat niet Damel, maar Daniel diende gelezen te worden. Enkele weken later kon de h. Lecureux deze lezing bevestigen ${ }^{2}$. Het is echter nog altijd niet uitgemaakt wanneer en hoe de klok in Bretagne is terechtgekomen.

De klok uit Pencran wordt ook vermeld in de bijdrage van A. Deschrevel over de klokken die door de klokkengieters De Leenknecht (alias Van Harelbeke) gegoten werden $^{3}$. Het is echter nog niet duidelijk welke familiebetrek-

2. $\mathrm{B}^{\text {on }}$ de Bethune, La cloche de Pencran, in Bul. Geschied en Oudh. Kring Kortrijk, 11 (1913-1914), 157-158; zie ook blz. 16, 51-52.

3. A. Deschrevel, Het klokkengietersgeslacht De Leenknecht (alias Van Harelbeke), in Biekorf, 60 (1959), 321-340 en 63 (1962), 297-301. 
king er was tussen de broers Daniel, Roger en (volgens de klok uit Deesdorf van 1373) Jan uit Kortrijk en de gebroeders De Leenknecht.

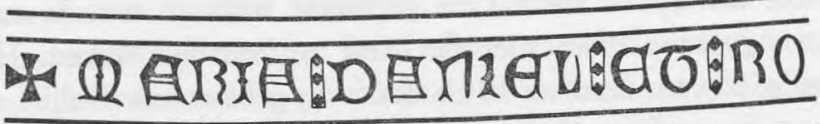

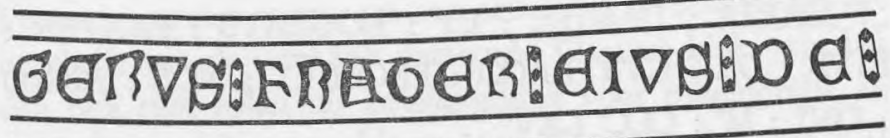

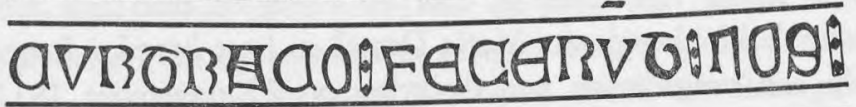
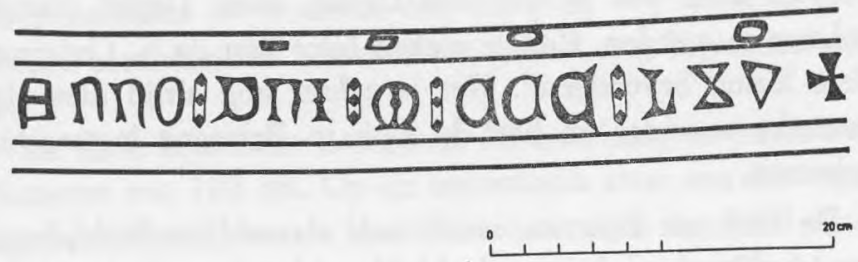

Inscbrift van de klok van Pencran, in werkelijkbeid op één regel gesteld.

L. DEVLIEGHER 


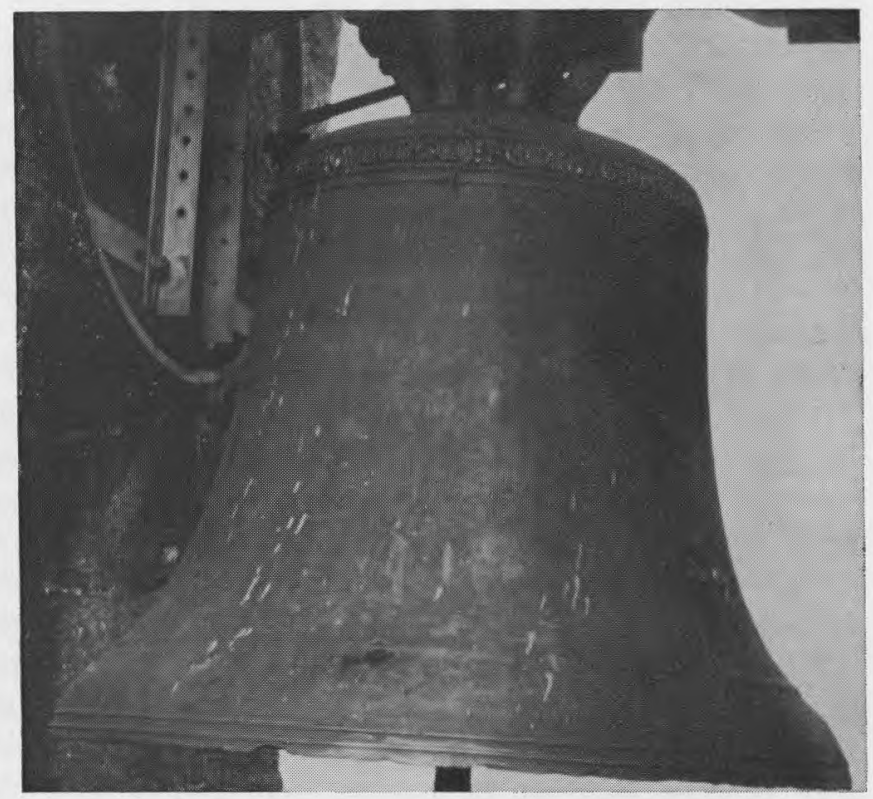

De Vlaamse klok van Pencran uit 1365. 